\title{
Comparison of Water Management and Rice Production among Farmer Groups in Large- and Small-Scale Irrigation Schemes: A Case Study of Rice Cultivation Near Lake Victoria in Western Kenya
}

\author{
Yuko Yamane ${ }^{1 *}$, Yoko Ichijo ${ }^{2}$, Jagath Kularatne ${ }^{1}$, Kasumi Ito ${ }^{1}$, Benedict Peter Obiero Owilla ${ }^{3}$ and Stellah Mukhovi ${ }^{4}$ \\ ${ }^{1}$ International Corporation Center for Agricultural Education, Nagoya University, Japan
}

${ }^{2}$ Tokyo University of Agriculture and Technology, Japan

${ }^{3}$ Ahero Irrigation Rice Research Station, Kenya

${ }^{4}$ Department of Geography and Environmental Studies, University of Nairobi, Kenya

Submission: December 03, 2018, Published: December 19, 2018

"Corresponding author: Yuko Yamane, International Corporation Center for Agricultural Education, Nagoya University, Nagoya-shi, Chikusa-ku, Furocho 464-8601, Japan

\begin{abstract}
Small-scale irrigation is generally recommended in Africa. However, very few studies have compared water consumption and crop yield between small- and large-scale irrigation areas. Thus, little empirical evidence that the former is superior to the latter exists. Three types of surveys were conducted to compare the conditions of rice cultivation between a large-scale cropping area and a small-scale irrigation area near Lake Victoria in western Kenya. First, cultivation experiments were conducted in Ahero and S Scheme that were large- and small-scale irrigation schemes, respectively. This allowed us to evaluate current rice cultivation and water management practices among groups of farmers, and gauge farmer participation. In the Ahero irrigation area, water was regularly supplied from the start of the cropping season, and rice cultivation proceeded without problems. In contrast, a water shortage occurred in the S Scheme from December to January, causing severe water-deficit stress to crops in some paddy fields. During this period, disputes over the available water arose among the farmers. Although the chairman of the group mediated these disputes, he failed to manage the water supply to preferentially benefit the paddy fields. In both organizational schemes, representatives of farmer groups were elected by the farmers every three years. In the Ahero Irrigation Scheme, three representatives are elected for each subblock. Based on our questionnaire, these three representatives were evaluated positively. Conversely, representatives of the S Scheme received a poor evaluation, especially for the chairman. In addition, although the evaluation was relatively good for the birth clan of the chairman, the other members of the clan were poorly evaluated. A field survey was conducted to compare rice yields, which revealed that all of 18 sites in the Ahero irrigation area exceeded the average yield for irrigated rice cultivation in Kenya. Conversely, in the S Scheme, highly contrasting yields were observed. Surprisingly, yields were high regardless of location relative to irrigation canals; indeed, high yields were observed in paddy fields throughout the area. Based on these results, water management in the large-scale irrigation area was more stable; evaluation of the activities of the farmer organization leaders was more favorable; and crop yields were higher. However, even in the small-scale irrigation scheme, high yields were obtained, regardless of location relative to irrigation canals; therefore, overall improvement is possible through efficient water management and technical assistance. Nevertheless, policy makers and aid agencies must consider the peculiarities of the local, traditional social organization.

Keywords: Irrigation scheme; Kenya; Large-scale irrigation; Rice cultivation; Small-scale irrigation; Water management
\end{abstract}

Abbreviations: WUAs: Water Users Associations; MiSS: Ministry of Social Service; PIU: Provincial Irrigation Unit; JICA: Japan International Cooperation Agency; NIB: National Irrigation Board

\section{Introduction}

Government and non-governmental agencies have invested considerable financial, technical, and organizational efforts in the construction and rehabilitation of irrigation infrastructure in developing countries. Irrigation management reforms have a

history of more than 50 years and have gained momentum over the past 20 years [1]. These reforms comprise a key component of government policy in most countries with an important irrigation sector [2]. The overall situation has been mixed in the approaches 
adopted in the design, implementation, extent, and impact of the reforms on irrigation-system performance, and on farmers [3]. However, since the mid-1980s, the centerpiece of the reforms invariably has been the transfer of management (and in rare cases, along with ownership) of irrigation systems, wholly or in part, to Water Users Associations (WUAs) or other non-governmental agencies, combined with the downsizing or even withdrawal of the government's role in operation and maintenance responsibilities, fee collection, water management, and conflict resolution [4].

In both East and West African countries, the introduction of rice cultivation accompanied by the development of large-scale irrigation facilities was attempted from the colonial period to the 1980s [5]. However, in some cases, it has not been possible to obtain any considerable benefits, owing to the failure to foster irrigation organizations, or the magnitude of investment. Thus, in the 1990s, criticism against the establishment of large-scale irrigation facilities intensified [6]. Because of the difficulty in managing large-scale irrigation in Africa, there is an increasing tendency to recommend small-scale irrigation [7]. Indeed, it is generally understood that large-scale irrigation systems do not function well in sub-Saharan Africa [8].

Irrigation schemes were established in Kenya during World War II (1939-45). The need to feed the British troops in East Africa during that time was another event that triggered irrigation development. This period marked the establishment of irrigation in the Kano Plain, among other areas. The efforts of the Government of Kenya in irrigation development after independence were focused mainly on establishing a largescale tenant-based irrigation scheme. After the war, the largest irrigation scheme in Kenya was established in Mwea from 1950 to 1960. A decade later, in the mid-1970s, three other schemes were established by the Kenyan government, Ahero, West-Kano, and Bnyala [9]. Nevertheless, management of the government-led irrigation projects did not succeed to the same extent as those in other African countries. Thus, in the 1990s, farmers demanded a substantial change in management policies. Since then, the basic policy on irrigated rice production has changed dramatically [1].

Although small-scale irrigation is also recommended in Kenya, information about the situation of rural water associations and rice cultivation is scarce. Therefore, as a first step, it is necessary to collect this information to provide adequate support.

A baseline survey was conducted on both large and small schemes within the study area (Figure 1a). The large-scale irrigation scheme evidently had a higher unit yield, and the rice cultivation management as perceived by the household was also favorable. Therefore, the purpose of this study was to evaluate and verify the conditions of irrigation and the management activities of the farmers' organizations, to determine the reasons behind the higher single-crop yield in the large-scale irrigated area. The members' assessment of the activities of the farmers' organizations was also investigated, and comparisons of the conditions of irrigation and rice production between large-scale and smallscale irrigation were drawn. To assess current relationships and challenges, the activities of farmer groups regarding irrigated rice water management in both large- and small-scale irrigation schemes were compared, and grain yield was assessed in each case, to clarify the relationship between water consumption and grain yield in the western coast of Kenya. Thus, a comparative study of rice cultivation and water management was conducted in both the large-scale irrigated rice cultivation area in the Ahero Irrigation Scheme (800ha), and one out grower of the S Scheme (about 120ha), an example of small-scale irrigation in a traditional area.

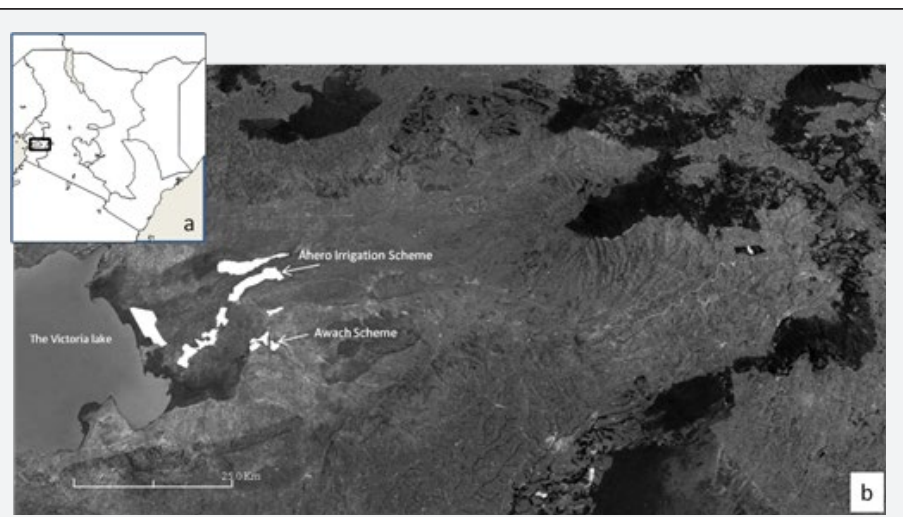

Figure 1: Location of study site in Kenya (a) and a distribution map of rice cultivation areas near The Lake Victoria (b).

\section{Materials and Methods}

\section{Study area}

Several rice cultivation areas are distributed over the Kano Plain $\left(0^{\circ} 04^{\prime} 0.20^{\prime \prime}\right.$; $\left.34^{\circ} 48^{\prime} 35.02^{\prime \prime} \mathrm{E}\right)$, east of Wynam Bay, on the eastern coast of Lake Victoria (Figure 1b) [10]. This plain lies at an elevation of approximately $1,140 \mathrm{~m}$ and is dotted with both seasonal and permanent wetlands close to the lake's shore. A recent report estimated that approximately 910ha of land is suitable for rice cultivation [11] in the plain. On the eastern side of the Kano Plain, a rift valley spreads as a topographical boundary between the plain and the Toydelett highland. Several rivers run down from this highland, the waters of which flow through the Kano Plain into Lake Victoria. Among them, the Nyand River 
and Awachi-Kano River are important water sources for rice production in the area.

There are two theories regarding the history of rice cultivation in the Lake Victoria region; one theory suggests that rice was already under cultivation by the beginning of the 20th century [12]; according to the second theory, rice cultivation was started by local farmers between 1930 and 1940 [10]. In any case, it seems that rice was cultivated before the Ahero large-scale irrigation scheme was constructed by the government in the 1970s. In this area, the river overflows every year around the rainy season, and the whole area, including the villages, is often damaged by flooding [13]. Thus, traditional rice cultivation declined after devastating floods destroyed many paddy fields in the 1960s [10]. Thereafter, irrigated rice cultivation resumed in the area from the mid-1960s to the 1970s, and the government responded to calls for large-scale irrigated rice production with the Ahero Irrigation Scheme (about 877ha), and the West-Kano Irrigation Scheme (900ha) introduced by the National Irrigation Board (NIB). The establishment of these irrigation projects began in 1969, when lands were distributed to farmers of 519 households at 1.6 ha per household.

The plain spreading through the Lake Victoria region of western Kenya is dotted with 11 small-scale rice cultivation areas called outgrowers (a total of 900ha) within the two large-scale, irrigated rice production areas constructed in the 1970s. This study aimed to compare rice cultivation and water management in both the large-scale irrigated rice cultivation areas of the Ahero Irrigation Scheme (800ha in 1974), and the outgrowers of the S Scheme (approximately 120ha), a traditional, small-scale irrigation area.

\section{Methods}

Information about the history of the Ahero Irrigation Scheme and the S Scheme, including construction details, the number of members cultivating each scheme, and details about the farmers' group managing water in the scheme was collected in 2010, 2011, 2012,2013 , and 2016, by asking the elders of each scheme about the respective situations.

Three experiments were conducted from September 2016 to April 2017. The first was a participant observation survey [14], a popular method used in anthropological studies as empirical research, to document water management by the farmers' groups and the relationships among rice farmers. The paddy fields of farmers in Block B of the Ahero Irrigation Scheme and the S Scheme were rented, and experimental rice cultivation was conducted in both rice fields. In the S Scheme, the first plowing was undertaken on September 22, 2016, and transplanting occurred on October 20, 2016. The harvesting date was February 17, 2017. Over the 150 days of the cropping season, the authors visited the experimental fields and stayed for 50 days to observe the situation. In the Ahero scheme, the first plowing was conducted in October, and transplanting occurred on December 24, 2016. The harvest date was April 17, 2017.
While taking part in joint work, such as maintenance of water canals or canal cleaning, the relationships among rice farmers and the conditions of the irrigation organization were observed. Thus, the second experiment included a semi-structured interview-survey of 62 households in four blocks of the Ahero Irrigation Scheme and 40 households in the S Scheme, through which information was collected about the farmers' awareness of the activities of the irrigation organizations, and the activities of the farmers' water user's association representatives were evaluated. Before evaluation, the names of each representative were confirmed to determine the number of individuals who could correctly identify their representative. Evaluation of three representatives of each farmers' group was then performed. Evaluations in each group were calculated as follows: very good (2 points); good (1 point); neither good nor bad ( 0 points); not good ( -1 point), bad ( -2 points). The average point value for each group was then calculated. During the calculations, evaluation points from individuals who did not recognize their representatives correctly were omitted.

Finally, our third experiment was a yield survey that documented rice productivity in farmers' fields. At harvest, rice plants were sampled (within an area of $1 \mathrm{~m} \times 1 \mathrm{~m}$ ) from 18 paddy fields in the Ahero Irrigation Scheme in Block B No. 2 during January 2017, and Block B No. 3 during April 2017. In addition, plants were sampled from 15 paddy fields in the a Irrigation Scheme from February-March 2017. The grain weight of each sample was measured, and productivity of each plot was calculated on a per unit area basis.

\section{Results and Discussion}

\section{History and situation of the Ahero irrigation scheme}

History: In the Ahero scheme, farmers were initially treated as tenants who functioned as a labor force and were provided with all the necessary inputs for rice production, including seed, fertilizers, pesticides, and water. After harvest, the grain produced was collected by the NIB, and farmers were paid the balance after considering production costs [15]. On the other hand, outgrowers distributed around the vicinity of the Ahero Irrigation Scheme were able to sell their harvest freely. The Scheme farmers gradually grew upset with the fact that they could not sell their harvest themselves. Thus, in Mwea, conflict between farmers in the NIB schemes and the NIB occurred and continued from 1998 to 2000. Farmers formed a cooperative group to manage the sale of their harvest and refused to sell to the NIB from 1998 to 2000 [16]. In Ahero, rice cultivation was stopped for three years, from 2000 to 2003, during which time the system shifted to farmerbased management. Furthermore, a WUA and a revolving fund group in charge of managing the farmers' funds were formed under the guidance of the NIB.

Currently, water management continues under the direction of the farmers' water users association with assistance from the NIB. In addition to the farmers' representatives that have been elected for each sub-block in the scheme, there is a central organization 
for these representatives that mainly controls the irrigation organization, the revolving fund, and the water consumption calendar of the whole scheme. The irrigation organization is a farmer organization, and its representatives are chosen on a subblock unit basis. They determine the times at which the flood gate is opened and closed. Irrigation organizations are responsible for preparing the yearly rice irrigation-plan for each sub-block on a monthly basis and distributing water in the area. If farmer groups of some sub-blocks do not pay the water fee, the water supply will be discontinued by the Water Use Association, and rice cultivation would not be possible during that year. Three representatives, the Chairman, Secretary, and Treasurer, who are elected by the members of a sub-block, are responsible for managing the activity of farmers who are organized in units.

\section{Participant observation of the situation of water management by famers}

Experimental rice (IR- 2804) cultivation was carried out from December 1, 2016 through April 17, 2017. According to the farmer organization, cultivation in Block B, where the experimental field was located, was supposed to start in October 2016. However, the water supply was not received into the irrigation canal in Block B before December. The reason for the delay was a water shortage in the river, which indeed, rarely receives any rain from September to December.

\section{History and situation of the small irrigation scheme: Awach scheme history}

Rice cultivation in A started in 1945, when it was established by the colonial government and a farmer group was formed that was registered with the Ministry of Social Service (MiSS) in 1986. That same year, the Provincial Irrigation Unit (PIU) under the Ministry of Agriculture developed irrigation infrastructure. Farmer training by the Ministry of Agriculture and Japan International Cooperation Agency (JICA) was conducted in 1999. Funding from the central government through the Constituency Development Fund (CDF) granted 500,000Ksh in 2005 and 150,000Ksh again in 2012. In 2014, the Kenya Government obtained 8.9 million Ksh as financial aid, and water intake was improved.
The S Scheme began rice cultivation around the 1940s before large-scale irrigation facilities were established. Irrigation facilities were constructed, and farmer groups were formed to manage water supply under the advice of the Kenyan governmental office of the PIU in the 1980s. Farmers obtain the funds necessary to start the crop, for example, by selling their livestock. All of the aforementioned rice cultivation areas are in the residential areas of the Luo people, who are descendants of the Nilote pastoral tribe. The village of Luo is formed from the paternal extended family. In the S Scheme, mainly two paternal families, the Kimira and the Katolo clans, grow rice.

\section{Participant observation of water management by the farmers}

An experimental rice crop was planted in the S Scheme from September 21, 2016 to February 20, 2017 to observe the situation of water management by the farmer groups. Our co-author, Yuko Yamane, attended seven out of the 38 appointed dates for collaborative work for maintenance of the water canal. However, the representative of the farmer group did not attend on those dates; thus, there are no records of the participants.

The irrigation fee (3,700Ksh) due on September 27, 2016 was considered as the maintenance cost of the main canal for the farmers in the group. The chief sometimes walks around the entire scheme to check the conditions of the scheme's canals. On November 25, observations were made of one main canal that had been breached in at least six locations, where farmers had diverted water into individual paddy fields. Although the chief tried to warn members against destruction of the canal, he did not have the authority to impose penalties on members, and the penalties themselves were unclear. Owing to the lack of rain in December, during the drought in January (Figure 2), the chairman of the farmer group had to settle quarrels that arose among the farmers. However, he did not adjust the irrigation schedule to distribute water to the blocks faced with water scarcity; thus, some fields remained barren because of the drought.

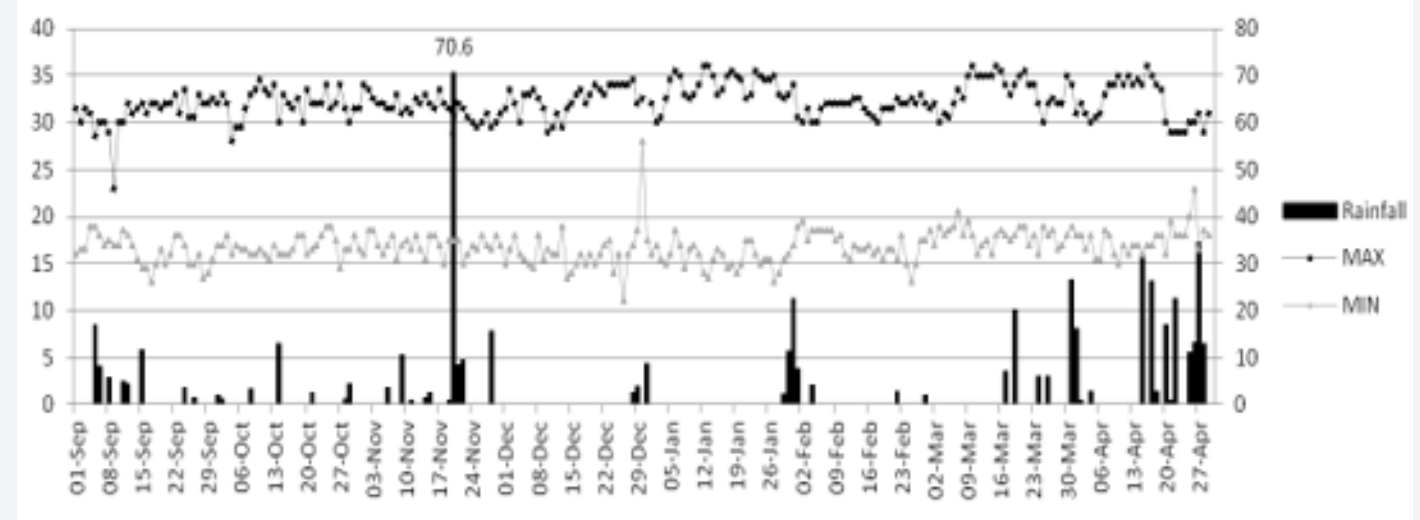

Figure 2: Daily rainfall and daily highest and lowest temperatures during the experimental period (acquired from the National Irrigation Board). 


\section{Water management}

Recognition of representatives by farmers of each scheme: IIn the Ahero scheme, no water conflicts occurred during the rice crop from December 1, 2016, to April 20, 2017, and water was supplied without interruption. However, the S Scheme suffered severe water shortages in January, resulting in intense competition among farmers. The chairman of the irrigation organization resolved these disputes but did not formulate an efficient water usage plan to be applied throughout the scheme. Individual farmers tried to obtain water and did so with a great deal of effort. These farmers were asked about their opinions of the overall situation and their evaluation of their representatives was sought.

Three representatives, the Chairman, Treasurer, and Secretary, are elected by members every three years in both the S Scheme and every sub-block of the Ahero Irrigation Scheme. Farmers in both schemes were asked the names of their three representatives and their evaluation of the representatives' performance was sought. Most members of each group knew the correct name of their chairman (Table 1). However, some members gave different names for the Secretary, if they did not know the correct name (Table 1). Regarding the Treasurer, differences were noted among the sub-blocks: in Block D, five out of seven members did not know the name of their Treasurer, and two stated another person's name (Table 1). Similarly, most members (30 out of 36) in the S Scheme did not know the name of their Treasurer. Regarding the Secretary, half of the members in Block D of the Ahero Scheme and one-third of the farmers of the $\mathrm{S}$ Scheme did not recognize the respective names (Table 1).

Farmer evaluation of the activities of the irrigation organization with in each scheme: Evaluations of the representatives were collected from the members of each group. Almost all members of both schemes knew the name of their chairman; however, the members of some groups did not recall the names of the other two representatives, even though they elected those individuals as their representatives. Regarding farmer evaluation of the activities of the representatives, in the Ahero Irrigation Scheme, the group Chief in all subgroups scored close to 1.0, indicating a favorable evaluation. However, evaluation of the
Treasurer and Secretary showed differences among the subgroups (Table 1). In contrast, farmer evaluation of the representatives of the S Scheme was lower than that of the Ahero Irrigation Scheme, particularly that of the Chairman, who was given a very poor score $(-0.04)$ (Table 1). Although the Chairman of the S Scheme received a good evaluation from those in his birth clan (0.25), in another - the Kimira clan, he was given a very low score by the farmers $(-0.16)$.

In the Ahero scheme, farmer evaluations of the three representatives were mostly good (Table 1). On the other hand, overall results in the S Scheme were not as favorable (Table 1); evaluation of the activities of the Chairman was the lowest in the S Scheme. Regarding farmer awareness of the irrigation situation, Table 1 shows that in response to the question of whether a problem existed with irrigation management, nearly $90 \%$ of the respondents in the S Scheme (35 out of 40) answered positively. On the other hand, in the Ahero scheme, only about 40\% (25 out of 62 people) acknowledged the existence of problems (Table 1). When asked about specific problems, members of the S Scheme indicated water shortages (12 out of 29 people) and inadequate water management (ten out of 29 people) (Figure 3). Moreover, in the Ahero Irrigation Scheme, farmers listed inappropriate management and a lack of cooperation as the main concerns (Figure 3).

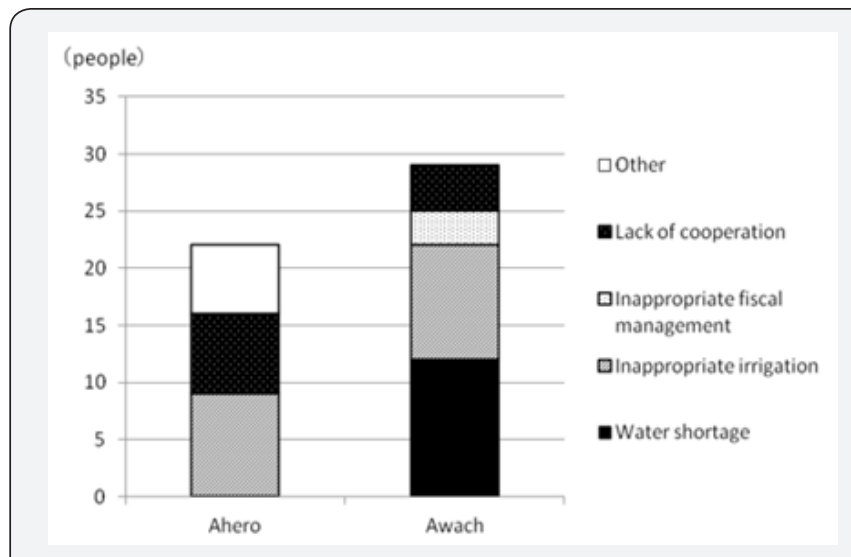

Figure 3: Identification of water management problems according to rice farmers in two irrigation schemes.

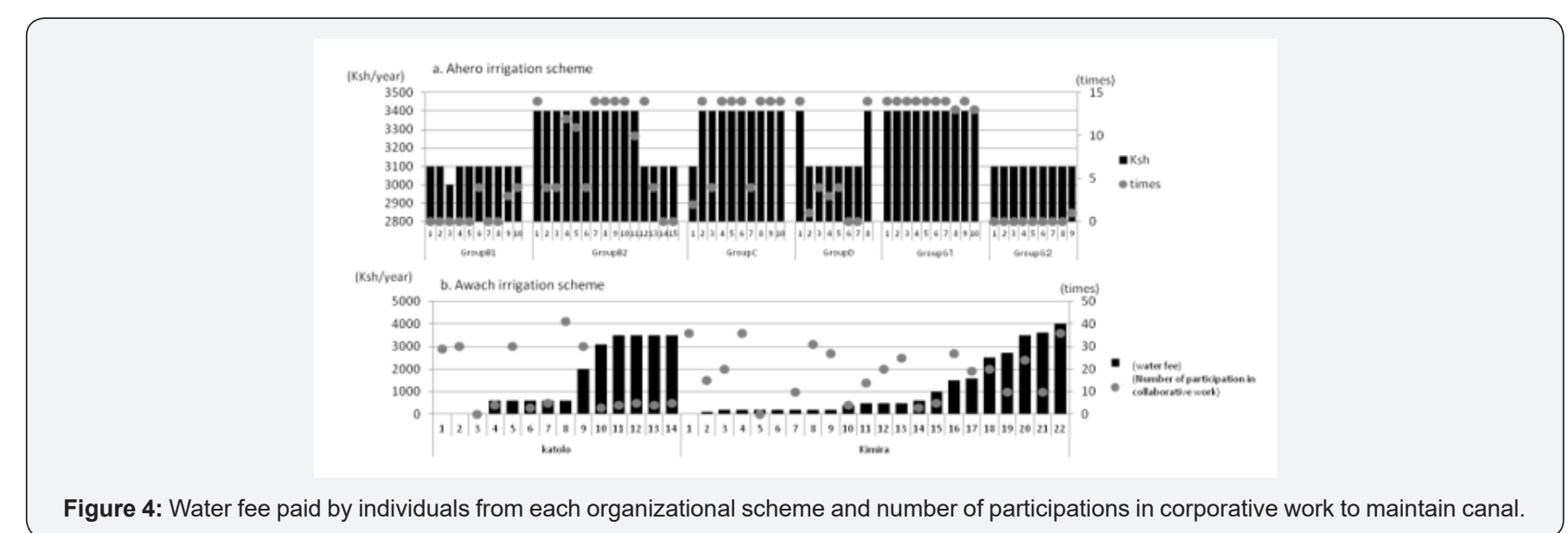


Participation in joint labor and payment of irrigation fee: When asked about participation in collaborative work, such as the maintenance of canals and farmer attendance, members in Blocks B No. 2, C, and G No. 1 of the Ahero Scheme responded that the number of active participants was relatively high, from 11-14 (Figure 4a). In contrast, more than half of the members in Blocks B No. 1, D, and G No. 2 admitted that they did not participate in collaborative work, and the number of participants was generally low (Figure 4a). In the S Scheme, most members participated in collaborative work with two clans, and the average number of instances of participation during the period under study was 18 (Figure 4b).

In the Ahero Irrigation Scheme, water is pumped from the river with a large electric pump. All farmers pay a fee of between 3,100 and 3,300Ksh/acre for the operation and maintenance of the main canal, and electricity cost for the water pump (Table 1). This is in contrast to the fee charged to each member of the $\mathrm{S}$ Scheme for canal maintenance (Figure $4 \mathrm{~b}$ ). In this case, since gravity is the driving force for water to move along the irrigation canal, regular maintenance of the canal is essential to repair any damage before the crop season begins. However, the number of times individual members participate in collaborative work varies, as well as the corresponding amounts paid in water fees. Farmers who cannot participate in repairs must instead pay a wage to secure labor. Thus, 10-14 households in Katolo that are frequently asked to participate in collaborative work, pay irrigation expenses as low as 200Ksh (Figure 4b). However, in Kimira, large variations were observed both in the irrigation fees paid and the number of participants involved in collaborative work (Figure $4 \mathrm{~b}$ ). The irrigation fee is not directly related to the number of active participants in collaborative work. For example, Block No. 5 neither participated in collaborative work nor paid an irrigation fee. In contrast, although sub-block No. 22 participated in collaborative work 38 times, farmers still paid 4,000Ksh/ household in irrigation fees in 2015 (Figure 4b).

\section{Rice cultivation}

Rice yield based on the interviews: The area of rice cultivation per household and the yield per hectare were calculated from the questionnaire. Whereas the average grain yield in the Ahero Irrigation Scheme was $5,042 \mathrm{~kg} /$ ha in 2015 , it was only $1,300 \mathrm{~kg} /$ ha in the S Scheme, which is less than one-third of the yield of Ahero. In particular, very low productivity was observed in the fields of the Katolo clan in the S Scheme. The average yield in this case did not exceed $500 \mathrm{~kg} / \mathrm{ha}$, approximately one-tenth that of the Ahero Irrigation Scheme.

Yield survey: Rice yield was evaluated in $1 \mathrm{~m} \times 1 \mathrm{~m}$ samples within two areas of Block B in the Ahero and S Schemes (Figure $5 a, 5 b)$. In the Ahero Irrigation Scheme, each sub-block is surrounded by a secondary canal, and members of each sub-block engage in collaborative work to maintain this secondary canal (Figure 5a). The average rice yield in Block B No. 1 was 6,316kg/ ha and that of No. 3 was 5,767kg/ha (Figure 5c). Although a slight difference was noted between the two sub-blocks, variation in yield was also noted within each sub-block. For example, yield in sub-block No. 10 reached almost 9,000kg/ha; however, that in subblock No. 11 was almost half that in No. 9, despite their proximity to each other. The IR rice varieties were planted in the region.
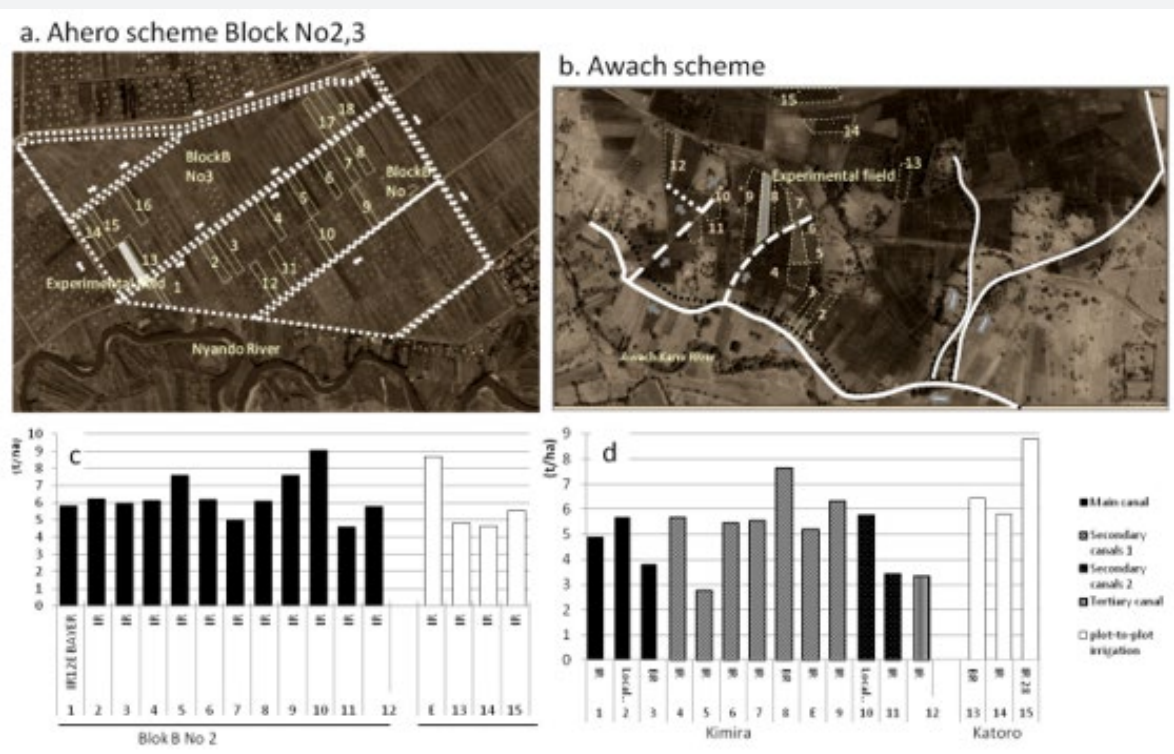

Figure 5: Result of crop yield survey in two schemes in 2017.

*The number of the sample points in schemes shown on the maps is the same as the number on the graph.

a. Map showing distribution of rice fields from which samples were collected for yield survey in the Ahero scheme Blocks No 2, and No

3.

b. Map showing distribution of rice fields from which samples were collected for yield survey in the Awach scheme.

c. Results of yield survey in the Ahero scheme.

d. Results of yield survey in the Awach scheme. 


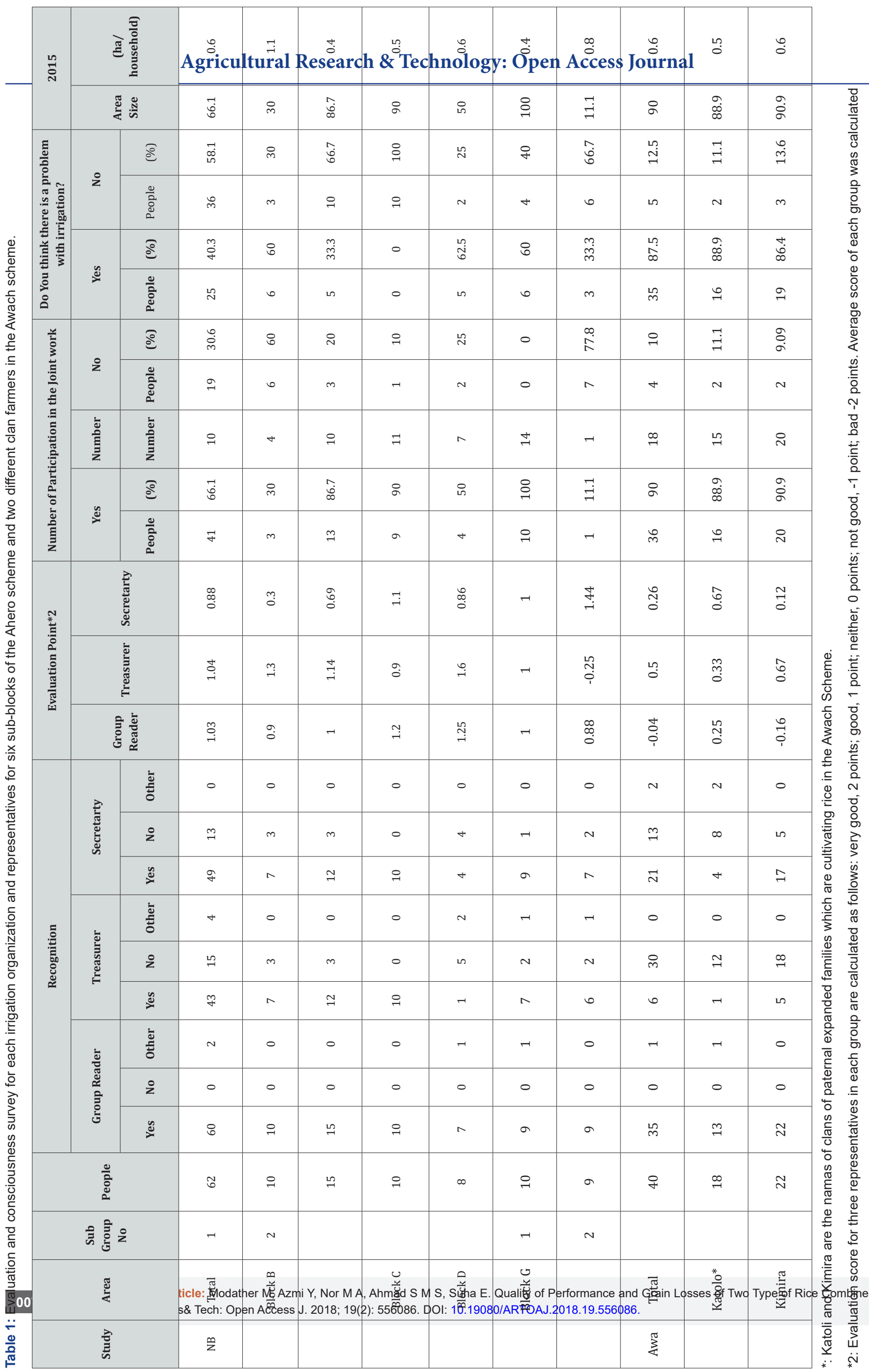


Moreover, yield also showed variation in the S Scheme (Figure 5b). The highest yield was nearly $8,000 \mathrm{~kg} / \mathrm{ha}$, and the lowest was barely one-fourth of that figure (Figure $5 \mathrm{~d}$ ). The varieties cultivated in many rice fields in A were IR, and a few plots were planted with BR, Basmati, or Aromatic varieties. Some other fields were cultivated with local varieties, namely Dorado and Nyaboda (Figure 5d).

In the S Scheme, the water distribution network is complicated. The main canal is divided into three parts at point A. In this scheme, members of the two clans cultivate rice, and each member gathers and distributes in their fields within several blocks. In the area of the Kimira clan, one of the three branches of the main canal distribute water.

The field Nos. 1-3 face the main canal (Figure 5b); Nos. 6-9 face the secondary canal; Nos. 4 and 5 are indirectly connected to the main and secondary canals, respectively, and receive water by plotto-plot irrigation. The field Nos. 10 and 11 also face the secondary canal but are at the end of the main canal (in comparison to Nos. 6-9), whereas No. 12 faces a tertiary canal.

Near the intake from the river, the main canal often has a higher water level than the secondary and tertiary canals, and it is supposedly easier to secure water from locations closer to the main canal [17]. Nonetheless, field location did not directly affect yield in the present study. For example, yields in field Nos. 1 and 2 , which were both in contact with the main canal, were close to $5,000 \mathrm{~kg} / \mathrm{ha}$, whereas in the adjacent field, No. 3, the yield was very low (less than $3,000 \mathrm{~kg} / \mathrm{h}$ ) (Figure $5 \mathrm{~d}$ ). On the other hand, the yield of paddy fields Nos. 6-9, at the end of the secondary canal, all of which exceeded $5,000 \mathrm{~kg} /$ ha, were higher than those of Nos. 1-3 (Figure 5d). In particular, the yield of field No. 8 was the highest, reaching close to $8,000 \mathrm{~kg} /$ ha (Figure $5 \mathrm{~d}$ ). In contrast, field Nos. 11 and 12 showed extremely low yields, barely reaching $3,000 \mathrm{~kg} / \mathrm{ha}$, which was not even half the yield of the nearby field No. 10 (Figure 5d). In addition, field Nos. 13-15, which belong to the Katolo clan, are far from the main canal, lacked any secondary canals, and were supplied with plot-to-plot irrigation (Figure 5d). Despite these disadvantages, the yield from these three paddy fields reached almost 6,000kg/ha in Nos. 13 and 14, and close to 9,000kg/ha in No. 15 (Figure 5d).

Inferences: Large-scale irrigation shows a record of poor performance in sub-Saharan Africa. As one notable example, substantial problems of escalating capital cost, construction delays, low yields, erratic water supply, poor management, and highly negative environmental and socio-economic impacts existed in the flooding plain-environment of many projects conducted in the 1970s and 1980s in Nigeria [5]. Similarly, the large-scale irrigation Mwe S Scheme, in the central part of Kenya, where massive irrigation facilities were constructed by the British colonial government in the 1950 s, has been rated poorly for rice cultivation. In many situations, management of these projects has degenerated into oppressive "spoils systems" that has destroyed all pre-existing informal institutions. Nowhere is this difficult situation more vivid than in the Mwea irrigation and settlement. Farmers eventually launched their own organization, changed the status of rice cultivation led by the NIB, and set up a system to sell products for rice cultivation at their own discretion. However, the system that led the farmers' organizations collapsed after just three years. There has not been a crisis [16], and to our knowledge, no report on the situation of farmer organization activities after that presently exists.

Water management: No conspicuous problems were detected in irrigated rice cultivation in the Ahero scheme of large-scale irrigation. Our experimental rice field, which aimed to document the water management situation of the Ahero Irrigation Scheme, started two months behind schedule; however, water was supplied without interruption thereafter.

Evaluation by members also showed a difference between the groups, with regard to attitudes toward the treasurers and secretaries; however, the evaluation of most representatives was relatively good. In addition, the irrigation fee applied to all members, who pay a uniform amount, and not to a targeted block. Under certain rules, however, the supply of water can be stopped to a block that has neglected to pay the irrigation fee. Water management was apparently being conducted without problems at the time of the survey. However, depending on the group, maintenance of the tertiary canal by collaborative work on a sub-block basis had a low frequency of participation, and the number of participants was low. Furthermore, about one-third of the respondents claimed there were challenges associated with irrigation and were aware of the irrigation and cooperation system.

On the other hand, in the S Scheme, an outgrower with a small irrigation system, management by irrigation organizations was not conducted under specific rules and norms. Instead, individual members secured water for their own paddies, and intense conflicts were observed during the drought. Rice cultivation started in October and ended in February; however, a water shortage lasting about one month, occurred from mid-December to mid-January. Although challenges arose with equipment irrigation based on gravity, immaturity of irrigation systems was also observed. In addition, conflicts over water arose among individual farmers, which the chairman mediated; however, no measures were taken to solve these disputes, such as diverting water to those fields where it was most needed. These conflicts resulted in a very poor evaluation of the activities of the chairman by most farmers, especially when compared to the corresponding situation in the Ahero Irrigation Scheme. In A, despite the differences in the water fee charged to each farmer, charging a fee that reflects individual participation in joint labor does not seem to be a good idea. Our results suggest that the rules of the game are universally accepted, and the consequences are clear. In addition, considerable differences were noted in compliance with the irrigation fee requirement and participation in joint labor among farmers. Management operations were apparently conducted 
according to a set of agreed-upon rules and were thus universally accepted by the farming community. Therefore, three-fourths of the respondents alluded to problems associated with irrigation, citing reasons such as water shortages, inadequate management of irrigation fees, inadequate irrigation, and a lack of cooperation.

Rice cultivation: In the Ahero Irrigation Scheme, seven sub-blocks had an average yield of 4.5 ton/ha, whereas in the a Irrigation Scheme, yields averaged about one-third of that figure. However, there were considerable differences in yield, depending on the specific paddy field. Some individual fields had high yields, and if water use and cultivation technology is improved, yield would surely improve as well.

Therefore, small is not necessarily more favorable in the context of irrigation, and support for small-scale irrigation as a target of development funding needs to be tempered with caution $[18,19]$. The most important feature of small-scale irrigation is its informal nature. In this case, challenges existed with operations, rather than the scale per scheme.

In Scheme, differences in consciousness were noted among the different clans, and the evaluation of a chairman by a clan from which he did not originate was very low. The traditional societal structure evidently still prevails, and the prospects for any adjustments in irrigation practices throughout the region are slim. According to the second of eight principles for the longterm commons by Ostrom [20], rules on water use are necessary to have to guarantee consistency with labor input for joint work and wages. However, as no legitimate relationship exists between the irrigation fee and the number of times members are required to participate in joint labor, the establishment of rules and mechanisms for individuals to comply with both are absolutely necessary. Furthermore, these rules and mechanisms must be accompanied by the establishment of penalties, to which everyone in the organization agrees. Thus, the success of small-scale irrigation schemes is dependent on the manner in which the farmers' organizations conduct their activities independently with minimal oversight. However, the prevalence of traditional relationships does not foster trust in reforms nor technology appropriation. External parties must support reforms in awareness and appropriate management.

\section{Conclusion}

Large-scale irrigation has a record of poor performance in subSaharan Africa. However, only a few studies specifically compare the conditions of water management and rice cultivation under large-scale irrigation with those under small-scale irrigation. In this study, irrigation, water management, and rice cultivation were compared between large-scale irrigation and small-scale irrigation in the Lake Victoria region in western Kenya. Although a few problems exist in large-scale irrigation areas with irrigation specifically, and in its management generally, members of the small-scale irrigated areas were dissatisfied with the procurement of irrigation fees, and the activities of the representatives. In addition, the yield of rice was higher in the large-scale irrigated area, even in cases where location-based differences were observed. Based on these findings, and with the exception of its lower operational costs, the features of small scale irrigation do not necessarily make it a good idea, in terms of its management and overall rice production. As Adams [21] points out, success depends on operation, irrespective of scale.

\section{Acknowledgement}

This study supported by Grant-in-Aid for Scientific Research C (:70528992).

\section{References}

1. Huggins C (2002) Water policy and law in a water-scarce country: Implications for smallholder irrigation in Kenya. In: Bank HG, et al. (Eds.), The changing face of irrigation in Kenya: Opportunities for anticipating changes in eastern and southern Africa. IWMI, 2002: 277300.

2. Chambers R (189) Editorial introduction: Vulnerability, coping and policy. IDS Bulletin 20(2): 1-7.

3. Sheikh MJ (2015) Farmers' participation, social capital and benefits in water management in SINDH province in Pakistan. Ph.D. Thesis, University PUTRA Malaysia, p. 77.

4. Nishimura Y (2009) Agriculture · Rural development and technology development · Technology transfer. In: Otubo S, Kimura H, Ito S (Eds.), Introduction for International Development Studies- Interdisciplinary Development Studies. Kusaka Syobo, 334-343.

5. Adams WM (1991) Large scale irrigation in northern Nigeria: Performance and ideology. Trans Inst Br Geogr 16(3): 287-300.

6. Hanzawa K (1990) Rice production and irrigation development in Sub Saharan Africa. A case from Kenya. Japanese Society for Tropical Agriculture 34: 107-114.

7. Shah T, van Koppen B, Merrey D, de Lange M, M Samad (2002) Institutional alternatives in African smallholder irrigation. Lessons from international experience with irrigation management transfer Research Report 60 International Water Management Institute, Colombo, Sri Lanka, p. 24.

8. Ishii Y (2001) Introduction of irrigation development in the southern part of the plain surrounding Mount Kenya. History of establishment of the Mwea Irrigation Project Area. African Report JETRO, p. 32-35.

9. Ngigi S (2002) Part 1. Setting the context review of irrigation development in Kenya. The changing face of irrigation in Kenya: Opportunities for anticipating changes in eastern and southern Africa. In: Bank HG, CM Mutero and H Murray-Rust (Eds). IWMI, p. 35-54.

10. Niemeijer R, Geuns M, Kliest T, Ogonda V, Hoorweg JC (1985) Nutritional aspect of rice cultivation in Nyanza province, Kenya. African Studies Center, Leiden, (Netherlands), p. 156.

11. Romano K (2009) Food Security in Kenya. Permanent Secretary Ministry of Agriculture. Ministry of Agriculture, p. 31.

12. Njokah JN (1984) Rice improvement in Eastern, Central and Southern Africa. Proceedings of the International Rice Workshop at Lusaka, Zambia. International Rice Research Institute (Laguna, Philippine), pp. 152.

13. Rarieya M, K Fortun (2010) Food security and seasonal climate information: Kenyan challenges. Sustain Sci 5(1): 99-114.

14. Maxwell J (2005) Qualitative Research Design: An Interactive Approach ( $3^{\text {rd }}$ edn), Applied Social Research Methods, SAGE Publications, London, pp. $87-121$. 
15. Okkidi CO (1990) Irrigation activities and institutions in Kenya's Lake Victoria Basin. Nat Resour Forum 14(2): 106-119.

16. Ishii Y (2007) Ethnography of the development frontier: People living in the East African irrigation program. Tokyo: Ochanomizushyobo, pp. 291.

17. MOA (Ministry of Agriculture) (2009) National Rice Development Strategy of Liberia Doubling Rice Production by 2008-2018. p. 52.

18. Fung-Lam W (1996) Improving the performance of small-scale irrigation systems: The effects of technological investments and governance structure on irrigation performance in Nepal. World Dev 24(8): 1301-1315.

19. Hunt RC (1988) Size and the structure of authority in canal irrigation systems. J Anthropol Res 44(4): 335-355.

20. Ostrom E (2015) Governing the commons. The Evolution of institutions for collective action. Cambridge, Cambridge University Press, p. 295.

21. Adams WM (1990) How beautiful is small? Scale, control and success in Kenyan irrigation. World Dev 18(10): 1309-1323.

\section{Your next submission with Juniper Publishers will reach you the below assets}

- Quality Editorial service

- Swift Peer Review

- Reprints availability

- E-prints Service

- Manuscript Podcast for convenient understanding

- Global attainment for your research

- Manuscript accessibility in different formats

( Pdf, E-pub, Full Text, Audio)

- Unceasing customer service

Track the below URL for one-step submission https://juniperpublishers.com/online-submission.php 